\title{
Coaches' perceptions on qualities defining good adolescent rugby players and are important for player recruitment in talent identification programs: the SCRuM project
}

\author{
M. Chiwaridzo ${ }^{1 *} \mathbb{D}$, N. Munambah, 2, S. Oorschot ${ }^{3}$, D. Magume ${ }^{4}$, J. M. Dambi ${ }^{5}$, G. Ferguson ${ }^{1}$ \\ and B. C. M. Smits-Engelsman ${ }^{1}$
}

\begin{abstract}
Objective: Competitive rugby is increasingly becoming popular among adolescent players even in countries hardly known for rugby such as Zimbabwe. Given the increased participation rates, burgeoning talent identification (TID) programs and the reportedly high injury-risk associated with competitive youth rugby, the minimal qualities or skills needed for effective performance by all young players need further clarification. Therefore, this qualitative study was conducted to explore the perceptions of high-school based rugby coaches on the key qualities or skills defining good adolescent rugby players and should be considered for player recruitment in TID programs. Currently, there is no consensus in literature from the coaches' perspective on these qualities.

Results: The final sample had 22 coaches (median age $=45.5$ years) with years of coaching high-school rugby ranging from 6 to 17 years. Using the conventional approach to inductive content analysis four broad themes emerged suggesting the multifaceted nature of the requirements imperative for effective and optimal rugby performance among adolescent rugby players as perceived by the coaches. Themes identified included: physiological characteristics, anthropometric attributes, psychological qualities and game-specific skills. Possibly, training approaches or design of rugby-specific test-batteries should consider all these important qualities and be multi-dimensional in composition.
\end{abstract}

Keywords: Rugby, Perceptions, Qualities, Skills, Attributes, Qualitative study, Coaches

\section{Introduction}

Globally, the number of adolescents playing competitive rugby is increasing even in countries where rugby is still developing such as Zimbabwe [1-3]. Due to high injury risk associated with rugby [4-7], adolescents playing competitive rugby should possess qualities needed for competition. Rugby is a physically challenging sport requiring specialist training of participants in preparation of the physiological demands and sporadic intensities $[8$,

\footnotetext{
*Correspondence: mchiwaridzo@medsch.uz.ac.zw

1 Division of Physiotherapy, Department of Health and Rehabilitation Sciences, Faculty of Health Sciences, University of Cape Town, Cape Town, South Africa

Full list of author information is available at the end of the article
}

9]. Hence, coaches should ensure that young players have qualities commensurate with rugby demands [10-12].

The need for talented young rugby players is a longterm vision for many countries [13]. Consequently, rugby bodies are constantly developing models for early identification of athletes [14-16]. Furthermore, demand for knowledge on rugby requirements continues to stimulate research on qualities discriminating players [17-19]. Previous studies have shown that anthropometric, physiological, rugby-specific skills and psychological attributes either determine team selection or discriminate rugby players by playing abilities [20-23], indirectly suggesting qualities important for rugby. However, little is known whether rugby coaches' value these identified qualities 
or have different perceptions based on practical and contextual experience. Currently, literature is equivocal on the qualities coaches perceive important or should be emphasised for training [24]. In Zimbabwe where highschool rugby is still developing and mainly played by school boys, it is interesting to explore what local coaches perceive as the most important qualities characterising good adolescent rugby players and are important when recruiting young rugby talent. Such studies potentially inform composition of future test batteries designed for talent identification (TID) programmes. Therefore, the present study sought rugby coaches' perceptions on qualities defining a good adolescent rugby player and are important for consideration in player recruitment in TID programs.

\section{Main text}

\section{Study design, setting and participants}

A qualitative study design was employed to determine qualities characterising good adolescent rugby players from coaches' perspective. This study was part of a project called the School Clinical Rugby Measure (SCRuM) partly described elsewhere [25, 26]. The present study targeted coaches of high-school male adolescent rugby players in Zimbabwe and was conducted at a school hosting the 2017 Dairiboard Zimbabwe Schools Rugby Festival (DZSRF). The festival is an annual national youth rugby tournament featuring rugby-playing primary and secondary schools. Reportedly, 150 schools participated in the 7-day long tournament in 2017 [27]. The concept behind DZSRF is similar to the national youth rugby tournaments held in South Africa designed for U-13 to $\mathrm{U}-18$ rugby players [28-31].

\section{Sampling and eligibility criteria}

The coaches were selected with an apriori intention of maximum heterogeneity within the sample. This entailed purposively-recruiting coaches from schools playing in the three high-school rugby leagues. The leagues include the Super Eight Schools Rugby League ("elite league"), Co-educational School Rugby League ("sub-elite") and the Interscholastic High Schools Rugby League ("amateur league") [26]. Firstly, a list of all participating high schools was obtained from the DZSRL director. The schools were then stratified into three categories representing the domestic high-school rugby leagues. Out of the 42 coaches approached from various schools, 22 volunteered to participate. The participants' demographic characteristics and rugby-related information are presented in Table 1. However, full-time rugby coaches with at least 5 years of Under-13 to Under-19 coaching experience were eligible. Additionally, coaches previously involved in TID programmes were purposively recruited for that unique experience.

\section{Procedure}

Ethical approval was granted by the Human Research Ethics Committee (HREC) of the University of Cape Town (reference: 016/2016). Participant identification and data collection were conducted between 30 April and 6 May, 2017, with at least two interviews scheduled per day. Coaches were directly approached by the first author seeking participation. A verbal explanation highlighting the rationale and study procedural issues was given. Potential participants were also left with information letters further detailing study purpose and methodology. Interview appointments would be set with the willing coaches, agreeing on the most convenient time and place for the interview.

On agreed dates, coaches would be invited to a quiet classroom specifically allocated for the interviews. Prior to the interviews, participants provided written informed consent and were verbally assured that the information provided was confidential. Coaches' demographic and rugby-related information was elicited first. Subsequently, a trained research assistant conducted semistructured face-to-face interviews in English since all participants understood and spoke the language. The interviews were based on a face-and-content validated English interview guide (Additional file 1) specifically developed and pre-tested for this study. Participants were probed for clarity and elaboration when necessary. All the interviews were audio-recorded and lasted between 15 to $40 \mathrm{~min}$.

\section{Data analysis}

For this article, we only analysed transcribed data from the second part of the interview guide. The interview data was transcribed verbatim by an independent person. Subsequently, the transcripts were proof-read by the first author against the original audio material verifying transcription accuracy. Noted discrepancies were discussed with the interviewer and transcriptor for a mutual consensus. Participant checking of the transcripts was then conducted with a convenience sample of rugby coaches $(\mathrm{n}=12)$. Data analysis commenced immediately after member checking. The manifest and latent content of the transcriptions was analysed according to the conventional approach of inductive content analysis to generate categories and themes [32-34]. Conventional content analysis is commonly used to analyse textual data preferably when literature on a phenomenon is limited [32]. Literature documenting coaches' perceptions on qualities defining good adolescent rugby players is sparse. Content analysis of textual data was manually conducted by 
Table 1 Sample demographic characteristic and rugby-related information $(\mathbf{N}=\mathbf{2 2})$

\begin{tabular}{|c|c|c|}
\hline Characteristic & Response & n (\%) \\
\hline \multirow[t]{2}{*}{ Type of school coached } & Government & $10(45.5)$ \\
\hline & Private & $12(54.5)$ \\
\hline \multirow[t]{3}{*}{ High-school rugby league the school plays in ${ }^{a}$} & Super Eight Schools Rugby League (elite) & $11(50.0)$ \\
\hline & Coeducational Schools Rugby League (sub-elite) & $5(22.7)$ \\
\hline & Interscholastic Schools Rugby League (amateur) & $6(27.3)$ \\
\hline \multirow[t]{3}{*}{ Age of the participants (years) } & $30-39$ & $3(13.6)$ \\
\hline & $40-49$ & $16(72.8)$ \\
\hline & $50+$ & $3(13.6)$ \\
\hline \multicolumn{3}{|l|}{ Median age (45.5 years) } \\
\hline \multicolumn{3}{|l|}{ Interquartile range $=42-49$} \\
\hline \multirow[t]{2}{*}{ Number of years coaching high school rugby in total (years) } & $\leq 9$ & $16(72.7)$ \\
\hline & $10+$ & $6(27.3)$ \\
\hline \multirow[t]{5}{*}{ School rugby team currently being coached } & Under $13 \mathrm{~s}$ & $1(4.5)$ \\
\hline & Under $15 \mathrm{~s}$ & $2(9.1)$ \\
\hline & Under $16 \mathrm{~s}$ & $5(22.7)$ \\
\hline & Second team & $5(22.7)$ \\
\hline & First team & $9(40.9)$ \\
\hline \multirow[t]{5}{*}{ Number of years coaching current school rugby team (years) } & $1-2$ & $7(31.8)$ \\
\hline & $3-4$ & $8(36.4)$ \\
\hline & $5-6$ & $3(13.6)$ \\
\hline & $7-8$ & $3(13.6)$ \\
\hline & $9-10$ & $1(4.5)$ \\
\hline \multirow[t]{2}{*}{ Other rugby coaching experience } & Yes & $4(18.2)$ \\
\hline & No & $18(81.8)$ \\
\hline \multirow[t]{2}{*}{ Have played rugby in lifetime } & Yes & $22(100)$ \\
\hline & No & $0(0)$ \\
\hline \multirow[t]{2}{*}{ Years played rugby in total (years) } & $1-9$ & $3(13.6)$ \\
\hline & $10+$ & $19(86.4)$ \\
\hline
\end{tabular}

a Super Eight Schools Rugby League represents the best high school rugby league in the country featuring eight top rugby playing high schools in the country. The league is regarded as the "elite" league. Co-educational Schools Rugby League represents the second most competitive league in the country (sub-elite) and the Interscholastic Schools Rugby League represent high school rugby league for the rest of the schools playing rugby in the county mainly composed of amateur players

the first author following steps of decontextualisation, recontextualisation and categorisation as described in literature [35]. A summary of the analytical process is provided in Additional file 2.

\section{Decontextualisation}

Firstly, the first author read several times the entirety of transcribed data. This process of "immersion" was to gather a general understanding of the data [32, 34-36]. Then, each transcript was carefully read specifically highlighting sentences or phrases (meaning units) expressing qualities defining good rugby player. The highlighted meaning units were then "copy-pasted" onto a new document and further condensed into smaller meaning units, called condensed meaning units [34,35]. The next step involved inductively creating an initial code list from the condensed meaning units of three randomly selected transcripts in a process called open-coding [32, 37]. This process was done to minimise change of the codes during the process of coding rest of the transcripts [35]. Using the generated code list as a guide, the first author then coded rest of the 19 transcripts and adding new codes when necessary [32].

\section{Recontextualisation and categorisation}

After coding, the first author read several times the meaning units, condensed meaning units and emergent codes to confirm or re-code the condensed meaning units. Subsequently, the researcher "copy-pasted" all the emergent codes onto a Microsoft Excel document, comparing the codes for possible similarities and differences [36]. Similar codes were coalesced and different codes remained distinct. Codes were then sorted into sub-categories and furthermore, into categories for the manifest 
content. Finally, the underlying meaning of the categories representing the latent content of the data was examined generating themes [36]. Although coding was undertaken by the first author, investigators' triangulation was conducted to validate the process. This was done by having the second (NM) and third authors ( $\mathrm{SO}$ ) code the transcriptions independently and derive own categories and themes. The authors (MC, SO, NM) had to compare the coding, sub-categorisation, and categorisation, discussing reasons for developed themes. Differences were solved by revisiting textual data, derived meaning units and condensed meaning units, and mutually re-coding the data, and agreeing on appropriate sub-categories, categories and themes.

\section{Results}

The four major themes representing qualities defining good adolescent rugby players and are important for player recruitment in TID programs that emerged from the coaches perceptions were: (i) physiological characteristics, (ii) anthropometric attributes, (iii) game-specific skills, and (iv) psychological qualities (Table 2). Additional file 3 further depicts emergent codes and illustrative quotes from selected coaches in detail.

\section{Discussion}

The present study revealed ten categories under physiological qualities, confirming findings from previous studies that rugby requires possession of many physiological qualities $[17,24]$. Muscular strength and power were perceived to be crucial in match situations involving aggressive contact, lifting, tackling, running and scrummaging. Rugby is a full-contact sport warranting optimal muscular strength and power [38-40]. There is compelling evidence that muscular strength and power discriminates rugby players for team selection [41-43]. Endurance and anaerobic capacity were also perceived to be important. The coaches felt that rugby players should show excellent recovery after repeated engagements in physical episodes. This is because rugby is an intermittent sport characterised by high-intensity anaerobic activities separated shortly by low-intensity aerobic activities and rest $[12,44,45]$. Elite junior rugby league players were previously found to have superior maximal aerobic capacity when compared to sub-elite players [46, 47]. Speed, aerobic capacity, muscular endurance, and body mass predicted players selected for junior rugby teams [23]. In the present study, coaches' perceived speed as important and emphasised the importance of running ability. There is evidence correlating speed and repeated-sprint ability to game performance such as tackle breaks and tries scores [19]. Also, previous studies illustrated the importance of speed and agility [46, 47].
Anthropometric qualities such as appropriate height and optimal body mass were also perceived as important. In support, significant differences were found in body mass and composition between U-14 rugby players playing competitive rugby compared to those playing at a more recreational level [43]. Skin-fold thickness significantly contributed to the discriminant analysis of selected and non-selected players in professional rugby league [41]. In a study observing changes in body size and anthropometric characteristics of U-20 rugby players, Lombard et al. [48] found that players became heavier and taller over time. Also, Darrall-Jones et al. [20] demonstrated significant increases across age categories for body mass and height. These findings reflect the nature of the sport which emphasise appropriate anthropometrics attributes for rugby players $[21,22,49,50]$.

Coaches also perceived passing, catching, tackling and ball-handling skills as important. These findings were also shared by other authors [39, 51-53]. Additionally, the coaches perceived that perceptual-cognitive skills including decision-making ability, game-sense awareness, anticipation, visual and auditory skills were important. Hendricks [39] reported almost similar findings. Professional rugby league players had better tackling proficiency, pattern recall (ability to read the game) and prediction ability (decision-making), and reactive agility when compared to semi-professional players $[54,55]$. Moreover, measures of technical and perceptual skills were associated with more line-breaks assists, try assists, and tackles completed during competition [56].

In the present study, psychological qualities were also perceived to be important although there are limited studies corroborating this evidence. Tredrea et al. [23] found no significant differences between selected and non-selected adolescent players for psychological attributes using the Mental Toughness (MT) Questionnaire. However, other studies involving adult players reported contrasting results using same tool [57]. Tredrea et al. [23] attributed that to reduced discriminative ability of MT tool in adolescents. Nevertheless, Larkin and O'Connor [58] found that perceived qualities such as "coachability" and "positive attitude" were important in soccer, an intermittent team sport like rugby. These findings were also shared by the coaches in the present study. The coaches felt that adolescent rugby players should be "teachable" and have personal attributes such as courage, determination, hardworking, discipline and passion for the sport.

In conclusion, coaches perceived physiological, anthropometric, and psychological and game-specific skills to be defining good adolescent rugby players. Therefore, training approaches or test-battery design should incorporate all these important qualities. Additionally, 
Table 2 Results of thematic analysis of coaches perceptions on qualities characterising good adolescent male rugby players $(\mathbf{n}=\mathbf{2 2})$

\begin{tabular}{|c|c|c|}
\hline Theme & Category & Sub-category \\
\hline \multirow[t]{15}{*}{ Physiological characteristics } & Muscular strength & Total body strength \\
\hline & & Upper-body muscular strength \\
\hline & & Lower-body muscular strength \\
\hline & Muscular power & Total muscular power \\
\hline & & Upper-extremity power \\
\hline & & Lower-extremity \\
\hline & Agility & Agility \\
\hline & Endurance & Endurance \\
\hline & Speed & Speed \\
\hline & & Repeated running \\
\hline & Anaerobic capacity & Anaerobic capacity \\
\hline & Balance & Balance \\
\hline & Coordination & Coordination \\
\hline & Muscle flexibility & Muscle flexibility \\
\hline & Repeated effort ability & Repeated high intensity effort \\
\hline \multirow[t]{3}{*}{ Anthropometric variables } & Physical qualities & Body mass \\
\hline & & Height \\
\hline & & Body composition \\
\hline \multirow[t]{17}{*}{ Game-specific skills } & Basic technical skills & Passing \\
\hline & & Kicking \\
\hline & & Catching \\
\hline & & Tackling \\
\hline & & Evasion \\
\hline & & Ball handling skills \\
\hline & & Defensive/offensive skills \\
\hline & Perceptual-cognitive skills & Auditory skills \\
\hline & & Visual skills \\
\hline & & Anticipatory skills \\
\hline & & Decision making \\
\hline & & Game sense \\
\hline & & Adaptability \\
\hline & Miscellaneous & Communication skills \\
\hline & & Leadership \\
\hline & & Competitiveness \\
\hline & & Team player \\
\hline \multirow[t]{8}{*}{ Psychological qualities } & Mental strength & Mental strength \\
\hline & Emotional stability & Emotionally stable \\
\hline & Attitude and personal traits & Positive attitude \\
\hline & & Courageous \\
\hline & & Determined \\
\hline & & Disciplined \\
\hline & & Teachable \\
\hline & & Passionate \\
\hline
\end{tabular}


consistent with the training periodisation approach [59], coaches may utilise this information during the coaching process and in improving player performance.

\section{Study limitations}

- Although generalisation of study findings is not important in qualitative studies, the 22 participants represented all the high-school rugby leagues in the country. Nevertheless, one major limitation was that data analysis was not conducted iteratively based on the saturation concept.

- Investigator triangulation of the coding process conducted provides credibility to the findings. However, credibility could have been enhanced by eliciting the perceptions of male adolescent rugby players' playing competitive school rugby and further, ensuring that member checking of the transcripts involved not only a convenience sample of 12 rugby coaches as used in the present study.

\section{Additional files}

Additional file 1. Interview guide for the qualitative study.

Additional file 2 . Summary of the qualitative content analysis process from data transcription to formulation of themes.

Additional file 3. Emergent themes, sub-categories, categories and themes from the interview data.

\section{Abbreviations}

DZSRL: Dairiboard Zimbabwe Schools Rugby Festival; HREC: Human Research Ethics Committee; MT: mental toughness; MRCZ: Medical Research Council of Zimbabwe; SCRuM: School Clinical Rugby Measure; TID: talent identification; U: under.

\section{Authors' contributions}

MC, BCM and GF originally developed the concept and design of the study. $M C$ acted as the lead investigator under the guidance and supervision of BCM and GF. At the time of writing this manuscript, MC was a doctoral student at UCT and this study was part of his on-going SCRuM project. MC conducted the literature review, recruited participants and conducted the initial data analysis with further triangulation of the coding, categorisation and theme formulation being performed secondarily by NM and SO. NM acted as the qualitative research expert, assisting with the face-and-content validation of the interview guide, training of the research assistant, qualitative analysis and interpretation of preliminary and main study results. DM acted as the primary research assistant performing the semi-structured interviews and memberchecking of transcribed data. MC and NM trained DM for the interviews in preparation for data collection. MC drafted the manuscript for publication and acted as the corresponding author throughout the review process. BCM, GF, $\mathrm{NM}, \mathrm{JMD}$ and SO performed critical revision of the initial version of manuscript which was submitted to the journal. BCM and GF continuously assisted with editing of the subsequent versions of the manuscript throughout the review process. All authors read and approved the final revised version of the manuscript submitted to the journal.

\section{Author details}

${ }^{1}$ Division of Physiotherapy, Department of Health and Rehabilitation Sciences, Faculty of Health Sciences, University of Cape Town, Cape Town, South Africa. 2 Division of Occupational Therapy, Department of Health and Rehabilitation Sciences, Faculty of Health Sciences, University of Cape Town, Cape Town, South Africa. ${ }^{3}$ Department of Rehabilitation, Academic Medical Center, University of Amsterdam, Amsterdam, Netherlands. ${ }^{4}$ Rehabilitation Clinic, Premier Service Medical Investment, 36 Josiah Tongogara, Avenue, Harare, Zimbabwe. ${ }^{5}$ Rehabilitation Department, College of Health Sciences, University of Zimbabwe, P.O Box, A178, Avondale, Harare, Zimbabwe.

\section{Acknowledgements}

The authors would like to acknowledge and thank the following people and institutions for their respective contributions to this study:

All the high-school rugby coaches who were interviewed in the pilot and main study data collection.

The Ministry of Primary and Secondary Education for the institutional permissions to access the research setting for data collection.

The headmaster of the school hosting the national youth rugby festival for granting permission to access the school and the local director for the rugby festival for providing list of schools participating in the rugby festival and helping with the classroom for the interview.

Local caretaker at the school hosting the rugby festival for making sure that the classroom for the interviews was smart.

Precious Chizanga for independently performing data transcription.

The members of staff of the Rehabilitation Department at the University of Zimbabwe, College of Health Sciences for the support during manuscript writing especially Mr Clement Nhunzvi, Ms Cathrine Tadyanemhandu and Ms Mildred Chikwanha for their invaluable input and insight during qualitative content analysis.

The first author acknowledges the mentoring and research training received from University of Zimbabwe College of Health Sciences PERFECT (Promoting Excellence in Research and Faculty Enhanced Career Training) program. The first author is a cohort 2 trainee under the mentorship of Professor James Hakim and Mrs Farayi Kaseke. The first author undertook a series of training lectures in qualitative research methodology and data analysis under PERFECT. The PERFECT program is supported by the Fogarty International Center of the National Institutes of Health under Award Number D43TW010137.

\section{Competing interests}

The authors declare that they have no competing interests.

\section{Availability of data and materials}

The datasets generated and/or analysed during the current study are not publicly available due to the fact that the data is part of ongoing research. However, the data are available from the corresponding author on reasonable request.

\section{Consent for publication}

Not applicable as the manuscript does not contain any data from any individual person.

\section{Ethics approval and consent to participate}

This study adhered to ethical principles under the Declaration of Helsinki. Institutional access and permission to conduct the study at a school hosting the Dairiboard Zimbabwe Schools Rugby Festival was obtained from Ministry of Primary and Secondary Education (Reference: C/426/3), Harare Province Education Director Office, and respective school headmaster. Ethical approval was sought and granted by the Human Research Ethics Committee (HREC) of the University of Cape Town (ref: 016/2016) where the first author is a registered doctoral student and, locally from Medical Research Council of Zimbabwe (Reference: MRCZ/A/2070) and the Joint Research Ethics Committee for the University of Zimbabwe, College of Health Sciences and Parirenyatwa Group of Hospitals (Reference: JREC 262/16). Participants provided written informed consent prior to participation following a verbal explanation and reading an information letter explaining the rationale and all procedural issues regarding the study. 


\section{Funding}

None.

\section{Publisher's Note}

Springer Nature remains neutral with regard to jurisdictional claims in published maps and institutional affiliations.

Received: 12 October 2018 Accepted: 11 March 2019

Published online: 13 March 2019

\section{References}

1. Bleakley C, Tully M, O'Connor S. Epidemiology of adolescent rugby injuries: a systematic review. Journal of Athletic Training. 2011;46(5):555-65.

2. Freitag A, Kirkwood G, Scharer S, Ofori-Asanso R, Pollock AM. Systematic review of rugby injuries in children and adolescents under 21 years. $\mathrm{Br}$ J Sports Med. 2015:49:511-9.

3. Chiwaridzo M, Masunzambwa Y, Naidoo N, Kaseke F, Dambi JM, Matare T. Profile of rugby injuries in high school Zimbabwean adolescents. Int J Sports Exerc Sci. 2015;1:5.

4. Collins $\mathrm{CL}$, Micheli LJ, Yard EE, Comstock RD. Injuries sustained by high school rugby players in the United States, 2005-2006. Arch Pediatr Adolesc Med. 2008:162(1):49-54.

5. Mclntosh AS, McCrory P, Finch CF, Wolfe R. Head, face and neck injury in youth rugby: incidence and risk factors. Br J Sports Med. 2010;44:188-93.

6. Brown JC, Verhagen E, Viljoen W, Van Michelen W, Hendricks S, Lambert MI. The incidence and severity of injuries at the 2011 South African Rugby Union (SARU) Youth Week tournaments. S Afr J Sports Med. 2012;24(2):49-54

7. Hislop MD, Stokes KA, Williams S, Mickay CD, England ME, Kemp SPT, et al. Reducing musculoskeletal injury and concussion risk in schoolboy rugby players with a pre-activity movement control exercise programme: a cluster randomised controlled trial. Br J Sports Med. 2017;51:1140-6.

8. Duthie GM. A framework for the physical development of elite rugby union players. Int J Sports Physiol Perf. 2006;1:2-13.

9. Read D, Weaving D, Phibbs P, Darrall-Jones J, Roe G, Weakley J, et al. Movement and physical demands of school and university rugby union match-play in England. BMJ Open Sport Exerc Med. 2017;2:e000147.

10. Archibold HAP, Rankin AT, Webb M, Nicholas R, Earnes NWA, Wilson RK, et al. RISUS study: rugby injury surveillance in ulster schools. Br J Sports Med. 2017:51:600-6.

11. Sclafani MP, Davis CC. Return to play progression for rugby following injury to the lower extremity: a clinical commentary and review of the literature. Int J Sports Phys Ther. 2016;11(2):302-20.

12. Hartwig $T$, Naughton $G$, Searl J. Motion analyses of adolescent rugby union players: a comparison of training and game demands. J Streng Cond Res. 2011;25(4):966-72.

13. Till K, Jones BL, Cobley S, Morley D, O'Hara J, Chapman C, et al. Identifying talent in youth sport: a novel methodology using higher-dimensional analysis. PLoS ONE. 2016;11(5):e0155047.

14. Durandt J, du Toit S, Borresen J, Hew-Butler T, Masimla H, Jakoet I, et al. Fitness and body composition profiling of elite junior South African rugby players. S Afr J Sports Med. 2006;18(2):38-45.

15. Spamer EJ. Talent identification and development in youth rugby players: a research review. S Afr J Res Sport Phys Educ Recr. 2009;31(2):109-18.

16. Abbott A, Button C, Pepping CJ, Collins D. Unnatural selection: talent identification and development in sport. Nonlinear Dynam Psychol Life Sci. 2005:9(1):61-88.

17. Chiwaridzo M, Oorschot S, Dambi JM, Ferguson GD, Booney E, Mudawarima T, Tadyanemhandu C, Smits-Engelsman BCM. A systematic review investigating measurement properties of physiological tests in rugby. BMC Sports Sci Med Rehabil. 2017;9:24.

18. Duthie GM, Pyne D, Hooper S. The applied physiology and game analysis of rugby union. Sports Med. 2003;33:937-99.

19. Smart D, Hopkins WG, Quarrie KL, Gill N. The relationships between physical fitness and game behaviours in rugby union players. Eur J Sport Sci. 2014:14(Sup 1):S8-17.
20. Darrall-Jones JD, Jones B, Till K. Anthropometric and physical profiles of English academy rugby union players. J Strength Cond Res. 2015:29(8):2086-96.

21. Jones B, Weaving D, Tee J, Darrall-Jones J, Weakley J, Phibbs P. Bigger, stronger, faster, fitter: the differences in physical qualities of school and academy rugby union players. J Sports Sci. 2018;36(21):2399-404.

22. Patton DA, McIntosh AS, Denny G. A review of the anthropometric characteristics, grading and dispensation of junior and youth rugby union players in Australia. Sports Med. 2016;46:1067-81.

23. Tredrea M, Descombe B, Sanctuary CE, Scanlan AT. The role of anthropometric, performance and psychological attributes in predicting selection into an elite development programme in older adolescent rugby league players. J Sports Sci. 2017;35(19):1897-903.

24. Jones TW, Smith A, Macnaughton LS, Duncan NF. Strength and conditioning and concurrent training practices in elite rugby union. J Streng Condition Res. 2016;30(12):3354-66.

25. Chiwaridzo M, Ferguson GD, Smits-Engelsman BCM. A systematic review protocol investigating tests for physical or physiological qualities and game-specific skills commonly used in rugby and related sports and their psychometric properties. Syst Rev. 2015;5:122.

26. Chiwaridzo M, Chandahwa D, Oorschot S, Tadyanemhandu C, Dambi JM, Ferguson $\mathrm{G}$, et al. Logical validation and evaluation of practical feasibility for the SCRuM (School Clinical Rugby Measure) test battery developed for young adolescent rugby players in a resource-constrained environment. PLOS ONE. 2018;13(11):e0207307.

27. Chitsiga T. Dairiboard commits to rugby fest. The Herald. 2017.

28. Durandt J, Parker Z, Masimla H, Lambert M. Rugby-playing history at the national U13 level and subsequent participation at the national U16 and U18 rugby tournaments. S Afr J Sports Med. 2011;23(4):103-5.

29. Hendricks S, O'Connor S, Lambert M, Brown J, Burger N, Mc Fie S, et al. Contact technique and concussions in the South African under-18 CocaCola Craven Week Rugby tournament. Eur J Sport Sci. 2015;15(6):557-64.

30. Burger N, Lambert MI, Viljoen W, Brown JC, Readhead C, Hendricks S. Tackle-related injury rates and nature of injuries in South African Youth Week tournament rugby union players (under-13 to under-18): an observational cohort study. BMJ Open. 2014:4:e005556.

31. Hendricks S, O'Connor S, Lambert M, Brown J, Burger N, Mc Fie S, et al. Video analysis of concussion injury mechanism in under-18 rugby. BMJ Open Sport Exerc Med. 2016;2:e000053.

32. Hsieh HF, Shannon SE. Three approaches to qualitative content analysis. Qual Health Res. 2005;15(9):1277-88.

33. Elo $\mathrm{S}$, Kyngas $\mathrm{H}$. The qualitative content analysis process. J Adv Nurs. 2008;62(1):107-15.

34. Erlingsson C, Brysiewicz P. A hands-on guide to doing content analysis. Afr J Emerg Med. 2017;7:93-9.

35. Bengtsson M. How to plan and perform a qualitative study using content analysis. NursingPlus Open. 2016;2:8-14.

36. Graneheim UH, Lundman B. Qualitative content analysis in nursing research: concepts, procedures and measures to achieve trustworthiness. Nurse Educ Today. 2004;24:105-12.

37. Hansen JL, Balmer DF, Giardino AP. Qualitative research methods for medical educators. Acad Paediatr. 2011;11:375-86.

38. Wang R, Hoffman JR, Tanigwa S, Miramonti AA, La Monica MB, Beyer KS, et al. Isometric mid-thigh pull correlates with strength, sprint, and agility performance in Collegiate rugby union players. J Streng Condition Res. 2016;30(11):3051-6.

39. Hendricks S. Trainability of junior rugby union players. S Afr J Sports Med. 2012:24(4):122-5

40. Appleby B, Newton RU, Corme P. Changes in strength over a 2-year period in professional rugby union players. J Strength Cond Res. 2012;26(9):2538-46

41. Gabbett TJ, Jenkins DG, Abernethy B. Relative importance of physiological, anthropometric, and skill qualities to team selection in professional rugby league. J Sports Sci. 2011;29(13):1453-61.

42. Gabbett TJ, Seibold AJ. Relationship between tests of physical qualities, team selection, and physical match performance in semi-professional rugby league players. J Strength Cond Res. 2013;27(12):3259-65.

43. Till K, Cobley S, Morley D, O'Hara J, Chapman C, Cooke C. The influence of age, playing position, anthropometry, and fitness on career attainment outcomes in rugby league. J Sports Sci. 2016;34(13):695-702. 
44. Suarez-Arrones JL, Portillo LJ, Gonzalez-Rave MJ, Munoz VE, Sanchez F. Match running performance in Spanish elite male rugby union using global positioning system. Isokinetic Exerc Sci. 2012;20:77-83.

45. Cunniffe B, Proctor W, Baker JS, Davies B. An evaluation of the physiological demands of elite rugby union using Global Positioning System tracking software. J Strength Cond Res. 2009;23(4):1195-203.

46. Gabbett T, Kelly J, Ralph S, Driscoll D. Physiological and anthropometric characteristics of junior elite and sub-elite rugby league players with special reference to starters and non-starters. J Sci Med Sport. 2009;12(1):215-22.

47. Till K, Cobley S, O'Hara J, Brightmore A, Cooke C, Chapman C. Using anthropometric and performance characteristics to predict selection in junior UK rugby league players. J Sci Med Sport. 2011;14(3):264-9.

48. Lombard WP, Durandt JJ, Masimla H, Green M, Lambert M. Changes in body size and physical characteristics of South African under-20 rugby union players over a 13-year period. J Strength Cond Res. 2015;29(4):980-8.

49. Bradley WJ, Cavanagh BP, Douglas W, Donovan TF, Morton JP, Close GL. Quantification of training load, energy intake, and physiological adaptations during a rugby preseason: a case study from an elite European rugby union squad. J Strength Cond Res. 2015;29(2):534-44.

50. Comfort P, Graham-Smith P, Matthews MJ, Bamber C. Strength and power characteristics in English elite rugby league players. J Strength Cond Res. 2011:25(5):1374-84.

51. Sayers MG, Ballon R. The Influence of Side Dominance on upper body kinematics during Rugby passes from the ground. In: 35th conference of the international society of biomechanics in sports, Cologne, Germany, June 14-18, 2017.

52. Linthorne NP, Stokes TG. Optimum Projection angle for attaining maximum distance in a rugby place. J Sports Sci Med. 2014;13:211-6.

53. Den Hollander S, Brown J, Lambert M, Treu P, Hendricks S. Skills associated with line breaks in elite rugby union. J Sports Sci Med. 2016;15:501-8.

54. Gabbett TJ, Ryan P. Tackling technique, injury risk, and playing performance in high performance collision sport athletes. Int J Sports Sci Coach. 2009;4:521-33.

55. Gabbett TJ, Wake M, Abernethy B. Use of dual-task methodology for skill assessment and development: examples from rugby league. J Sports Sci. 2011;29:7-18.

56. Gabbett TJ, Jenkins DG, Abernethy B. Relationships between physiological, anthropometric, and skill qualities and playing performance in professional rugby league players. J Sports Sci. 2011;29:1655-64.

57. Golby J, Sheard M. Mental toughness and hardness at different levels of rugby league. Person Individ Differ. 2004;37(5):933-42.

58. Larkin $\mathrm{P}, \mathrm{O}^{\prime}$ Connor $\mathrm{D}$. Talent identification and recruitment in youth soccer: recruiter's perceptions of the key attributes for player recruitment. PLOS ONE. 2017;12(4):e0175716.

59. Tee JC, Ashford M, Piggott D. A tactical periodization approach for rugby union. Strength Condition J. 2018;40(8):1-13.
Ready to submit your research? Choose BMC and benefit from:

- fast, convenient online submission

- thorough peer review by experienced researchers in your field

- rapid publication on acceptance

- support for research data, including large and complex data types

- gold Open Access which fosters wider collaboration and increased citations

- maximum visibility for your research: over 100M website views per year

At BMC, research is always in progress.

Learn more biomedcentral.com/submissions 